\title{
Online Practice Course Development with Action Research: A Case Example
}

\author{
Khadija Khaja \\ Phillip Ouellette \\ Carenlee Barkdull \\ Joanne Yaffe
}

\begin{abstract}
Despite the proliferation of online courses in social work, questions still exist about learning practice skills in an online instructional environment. This paper describes a case example of an action-oriented approach to the development of an online practice course. Lessons learned from students' and instructor's perspectives are shared as well as recommendations for future research relative to course development and evaluation of online courses. The study examined student feedback with respect to their overall learning experience. Findings indicated that involving students in the design and development of an online practice course benefited both students and faculty and can be an effective teaching and learning strategy regardless of the instructional medium used.
\end{abstract}

Keywords: Instructional design; technology; distance learning; online education; social work practice skills; action research

Computer technology has affected social work education in many ways. The rapid use and growth of internet technology have provided students and educators with opportunities to retrieve large quantities of information quickly from all over the world, and technological advancements have given rise to a wide array of multimedia teaching tools. These developments have contributed to increased demand for online social work courses in colleges and universities (Siebert \& Spaulding-Givens, 2006). Social work education in the $21^{\text {st }}$ century is experiencing a paradigm shift in which traditional classroom-based teaching is being supplemented or supplanted by technology-delivered instructional content.

While research would seem to indicate that there is no significant difference between the efficacies of learning outcomes with courses taught in an online learning environment versus those in a face-to-face classroom learning setting (Macy, Rooney, Hollister, \& Freddolino, 2001; Ouellette \& Chang, 2004; Ouellette, Westhuis, Marshall, \& Chang, 2006), social work educators still appear apprehensive about teaching practice courses in an online setting. In a field where interpersonal communication skills and use of self are emphasized, the development and implementation of online social work practice courses may be resisted by students, faculty and administrators due to the perceived need for face-to-face contact between instructors and students.

Khadija Khaja, Ph.D., is an assistant professor and Philip Ouellette, Ph.D., is an associate professor, both at the Indiana University School of Social Work, Indianapolis. Carenlee Barkdull, Ph.D., is the MSW Coordinator in the Department of Social Work at the University of North Dakota. Joanne Yaffe, Ph.D., is an associate professor in the College of Social Work at the University of Utah. 
A case study conducted within an action research framework was designed and implemented in collaboration with graduate students enrolled in a practice class in an effort to explore this question. Challenges and lessons learned through this collaborative process will be shared, as will implications for further research relative to social work practice classes in online learning environments.

\section{LITERATURE REVIEW}

Social work programs generally appear to be behind many other disciplines in using Web-based technology for offering their programs (Siebert \& Spaulding-Givens, 2006). Although many social work programs offer some baccalaureate and graduate level courses in an online setting, few are offering their degree programs entirely online. The resistance or apprehension of many social work faculty to teach curricula entirely online may be that "social work's focus on human connection and hands-on practice skills can seem antithetical to technology-mediated education" (Siebert \& Spaulding-Givens, 2006, p. 2). Hence, there has been lively debate and even controversy around teaching social work courses in an online environment. This resistance is beneficial to the field as it places a higher burden on social work educators to design online social work courses that are accountable to a profession that values human connectedness (Ouellette, Khaja, \& Westhuis, 2007).

\section{Increasing Use of Technology in Social Work Education}

Online course enrollment is clearly on the rise in the United States with enrollment in a number of disciplines increasing by as much as 33\% each year (Pethokoukis, 2002). In 2002, approximately 2.3 million students took online courses (Katz-Stone, 2000). In the academic year of $2000-2001$, about $90 \%$ of two-year public schools and $89 \%$ of public four-year academic institutions offered online courses (Waits \& Lewis, 2003).

The increased use of technology as an instructional medium has clearly continued to grow rapidly in the field of social work education as well. Distance technology can be employed to reach students in rural areas; for example, the use of technology has been successfully used to reach Aboriginal social work students in remote areas of Canada (Hick, 2002). Online social work courses are now offered to teach areas such as diversity, gerontology, policy, human rights, introduction to social work, international social work (Ouellette et al., 2007), advocacy (McNutt \& Menon, 2002), research (Westhuis, Ouellette, \& Pfahler, 2006), and clinical practice (Coe \& Elliot, 1999; Ouellette et al., 2006; Shibusawa, VanEsselstyn, \& Oppenheim, 2006). Other examples for integrating technology for teaching and learning practice skills include the use of digital practicum portfolios and online assessment tools (Lee, 2007).

There is also a growing body of literature relative to social work training that describes the use of various technological tools worldwide, from CD-ROMS and video disks to interactive web-based modules, both for students and those seeking additional professional development opportunities (Ballantyne, 2007; Menon \& Coe, 2000; Sandell \& Hayes, 2002; Shibusawa et al., 2006). Increasingly, communication technologies are 
also being employed as knowledge storage (Holden, 2002) and as possible delivery systems for reaching at-risk population groups (Ouellette \& Wilkerson, 2008).

\section{Characteristics of the Online Learner}

Studies have shown that students who tend to do well in independent learning environments generally succeed in their online courses (Tallent-Runnels et al., 2006); however, online learning environments may not be perceived as user-friendly by all students (Schrum, 1995). One survey of 70 academic institutions conducted by Schrum and Hong (2002) revealed that learner success in an online environment was predicted by eight characteristics, including access to the latest tools, technology experience, learning preferences, study habits, goals, purposes, lifestyles, and personal traits. In another study, nearly $42 \%$ of online students were not content with their learning experience if their instructors' sole teaching strategy was to simply post a great deal of written text online. Students preferred that instructors utilize more audio-visual technology in their online classes (Faux \& Black-Hughes, 2000).

\section{Teaching Practice Courses in Online Settings: Framing Questions}

The debate or controversy around the integration of computer technology for teaching practice courses in social work has prompted several critical and important questions: (1) What constitutes good teaching and learning in an online environment? (2) What can be done to assist faculty in integrating traditional teaching strategies to an online setting? (3) What leadership roles can administrators play to support an online learning culture?

For faculty, time for development of online courses is often a major barrier. Another issue is the necessity of developing a new set of technical skills to integrate technology into curriculum design. The authors have learned from their own experiences that one cannot simply mimic or transfer a traditional classroom-delivered social work course into an online environment without a major shift in how we think about what constitutes good learning via an electronic medium. In addition to the pedagogical challenges, many social work educators are not as savvy with technology as are their students and require considerable mentoring and support in this area (Ouellette et al., 2007).

The implications of alterations in student-instructor relationships must also be considered. It has been asserted that online learning environments shift considerable amounts of power, authority, and control from the instructor to the students because they are expected to demonstrate more initiative and must be motivated to learn independently (Jaffee, 1998). Others argue that online learning environments give a great deal of authority and power to the instructor, especially if students do not have easy access to the technological tools they need to engage in online learning (Ouellette et al., 2007).

The development of interpersonal skills is emphasized in social work practice courses, yet instructors may underestimate the difficulty in capturing feelings in online instructional settings (Tallent-Runnels et al., 2006). Some instructors have used emoticons such as smiley faces, pictures, and cartoon characters to create more of a relational atmosphere (Bielman, Putney, \& Strudler, 2000; Tallent-Runnels et al., 2006), 
but it is not known how successful these attempts to create a sense of interaction and community in the classroom really are.

Practice skills curricula focus intently on the nature of interpersonal interaction, including non-verbal communication, listening skills, empathy, and authenticity. Social work students are expected to learn how to simultaneously read and interpret the complex communications of others while monitoring and modeling high-level communication skills themselves. Mindful of the challenges mastering these skills presents, Siebert and Spaulding-Givens (2006) offer several recommendations for teaching clinical content in practice social work courses in an online setting. They suggest that instructors need to have taught clinical social work face-to-face for a number of years before even attempting to transfer this knowledge to an online setting; the course design must be able to capture feelings and emotions of students; video technology that illustrates exemplars of clinical skills should be available for students to see and hear in their online courses; publishing companies should make it easier and less complex for educators to use such materials; instructors with technology expertise need to be consultants or coaches to the process so that audio-visual interaction with students is available; and web camera communication technologies should be utilized to enable students to communicate with each other and to engage in practice role plays which can be reviewed by the instructor. While these recommendations are instructive and helpful, research related to how such practice-related skill sets can be developed and assessed in online learning environments is largely absent (Siebert \& Spaulding-Givens, 2006).

\section{The Case for Building Online Learning Communities}

One key question about teaching social work practice courses online is whether or not an online environment can contribute to the development of a community of learners (Tallent-Runnels et al., 2006). We assume that attention to this aspect of online pedagogy is particularly relevant for online social work practice courses in which students are expected to learn empathic communication skills as well as skills for relating to other professionals. Some have reported that students can form a learning community in an online environment where a sense of camaraderie, support, and warmth can be experienced (Johansen \& Ouellette, 2006). Others have suggested that online instructors can establish a community of learners early on by modeling and reinforcing effective communication techniques, identifying potential problems early in the course, and designing a plan of action for dealing with a lack of student interaction in an online class (Knupfer, Gram, \& Larsen, 1997).

Knupfer and colleagues (1997) found that collaboration and flexibility were critical to the success of online classes, yet instructors who promote collaborative learning environments in face-to-face classroom settings may find the online environment presents some real challenges to instructors in this regard (Ouellette et al., 2007). While social work educators embrace such concepts as the strengths perspective (Saleebey, 2006), empowerment, (Ellsworth, 1999) collaborative learning (George, 1999), and principles of adult learning (Knowles, 1980), the literature provides few illustrations of how students are actively involved with their instructors to contribute to the design, implementation, and evaluation of online courses. 
Fetterman (1996) defined empowerment as a process in which client selfdetermination is fostered. One of the prime roles of helpers is to help clients to realize that they can "gain control, obtain needed resources, and critically understand one's social environment" and "become independent problem solvers or decision makers" (Fetterman, 1996, p. 4). In many ways this empowering role is not so different from educators' roles. Empowerment at its best is a "collaborative group activity" that if successful creates a more "open forum” (Fetterman, 1996, p. 5). Research indicates that empowerment teaching models can help students take more responsibility in the design, implementation, and evaluation of their courses (Huff \& McNown-Johnson, 1998). Increased participation and collaboration by students with instructors to assist in conceptualizing design of a course may help to develop a "dynamic community of learners" (Fetterman, 1996, p. 4). In other words, if students feel that their voices count and that they can be trusted, they will develop greater confidence, initiative and leadership skills which will benefit their clients and communities. Other literature has indicated that when students are invited to share in the responsibility for actively defining mutually shared learning objectives with their instructor, they will subsequently take more interest in and responsibility for their own learning (Saleebey, 2006). Inevitably they begin viewing themselves as more responsible, competent, significant, empowered, and trusted (Ellsworth, 1999). Levin (1996) indicates that if one includes students in the process of a course design that it provides students with "unity of purpose," "responsibility," and builds upon student strengths (p. 52). Unity of purpose ensures an environment where students and faculty are working together in a collaborative culture that incorporates the setting of goals, standards, and a school community.

One major gap in the research is whether active student involvement in the design, development, and implementation of an online practice course could be helpful in making such courses more conducive to the learning needs of students. Hence, the central question for further study would be to explore to what extent student collaboration and student participation in course design actually contributes to learning of practice skills in an online environment. Students were asked the following research questions: How similar or different were online course modules to materials presented in the classroom? What ideas or concepts presented in online course modules needed more clarification? What online exercises or assignments were useful/not useful and why? What ideas or recommendations did students have to improve the quality of online course modules with special reference to suggestions on audio-visual presentations and practice exercises?

Although social work educators embrace principles of empowerment, collaborative learning, and adult learning, the literature does not appear to sufficiently address the role of the student or the adult learner in online course development, much less how this could be done in a practice course. Hence, studies that would investigate how student involvement impacts the development of effective course designs and how this could realistically be implemented in an actual course would further enhance our understanding of what constitutes good teaching and learning practices in an online setting. What follows is a description of such a study. 


\section{METHODS}

\section{Participants}

The lead author is an experienced social work practice instructor, but a novice to online course delivery. With assistance from a technologically-savvy social work colleague, she embarked on a journey to develop an online practice skills course using an incremental approach that would also harness the expertise and experience of social work practice students.

Graduate students in a three-credit, classroom-based, social work practice course at a large Midwestern university were offered the opportunity to voluntarily remain in the classroom environment for the entire course, or to opt for online instruction for the final one-third of the course (a five-week period). All twenty-nine students opted to enroll in the online segment. Twenty-one of the students in the participating class were female; the class was also relatively ethnically diverse. Students appeared intrigued both by the opportunity to provide feedback on their experience of the online modules in relation to the classroom segment, and to help evaluate newly-developed online course materials. The course was taught by an experienced practice instructor who is also a relative newcomer to online instruction.

\section{Procedure}

Action research was deemed most congruent with the purposes of this inquiry as it is concerned with both "practical knowing" and with participatory values (Reason \& Bradbury, 2001). An action research framework, which can incorporate any combination of methods appropriate to a given research question, was viewed as most appropriate to this line of practical pedagogical inquiry as it involves "stakeholders both in the questioning and sense making that informs the research, and the action which is its focus" (Reason \& Bradbury, 2001, p. 2). Thus, an action research framework was employed to recruit the active involvement and assistance of key stakeholders, i.e., social work students, in pursuit of a pragmatic objective: the development and evaluation of an online practice course segment that might serve as a "launching pad" for an eventual online offering. It was also hoped that this inquiry would help yield some broader insights into some of the thornier questions surrounding the teaching and learning of social work practice via online technology. In other words, instructors and students embark together on a journey of discovery as both co-teachers and co-learners, and commit together to the enterprise of mutual support and continuous improvement.

\section{Instruments}

The Web-based instructional materials were developed in collaboration with the second author, a fellow faculty member with many years of technological experience and technical expertise in designing online courses. A graduate research assistant, who had previously taken the practice course in a traditional classroom setting, was hired as a research assistant to help develop the new online class sessions or course modules, and to provide her unique insights as a former course student. 
The level of student participation in this effort was remarkable given that all students voluntarily provided feedback on an ongoing basis via anonymous online questionnaires after reviewing each online practice module. The questionnaires addressed the following questions: How similar or different were online course modules to materials presented in the classroom? What ideas or concepts presented in online course modules needed more clarification? What online exercises or assignments were useful/not useful and why? What ideas or recommendations did students have to improve the quality of online course modules with special reference to suggestions on audio-visual presentations and practice exercises?

\section{Data Analysis}

The course instructor and technological expert reviewed student feedback, recommendations, and suggestions, noted themes for each course module, and worked collaboratively to incorporate this feedback into the subsequent module. Making such responsive and action-oriented course adjustments necessarily entailed additional time and effort for everyone involved. The consistently high level of participation in the questionnaire process, however, reinforced the instructor's impressions that students were aware that their insights and input were valued and put to use in hopes of better promoting the dynamic process of learning.

\section{FINDINGS}

The findings in this study illustrated several themes that may be helpful for instructors who are considering teaching practice courses in an online learning environment. Some of the key themes that evolved form this action research initiative illustrated the following: (i) Students' online learning experience of an online practice course varied depending on their technology skill level. (ii) Students were generally surprised at the rigor of the online practice modules that were developed because initially they assumed it would not be challenging. (iii) Skeptical students found they learned practice skills effectively but still missed live interaction with peers and the instructor in the online setting.

\section{Student Learning Experience - Similarities and Differences}

Not surprisingly, students did not all share the same impressions of the classroom and online instructional environments. For instance, some reported that the materials in the online course modules were rigorous and demanding and provided more detailed practice information than what was presented in the classroom. Other students reported that both learning environments provided a great deal of information, and that both were comparable. In addition, some students did not feel that they were receiving the same kind of feedback from their classmates or instructor in the online context, while others indicated that, "it was not very different [online]." 


\section{Presentation of Online Course Materials}

Some of the Web-based materials for the online course modules were prepared using a variety of multimedia tools and software such as Impatica OnCue, Breeze Presenter, and streaming videos. As a result, the online materials included a significant number of audio-visual presentations, including taped videos of the instructor's lectures. Students were asked to evaluate how these presentations contributed to their overall learning experience in the online environment. The majority of students thought that the online lectures, presented through streaming video and audio-visual PowerPoint presentations were clear, well-presented, enjoyable, and user-friendly. One student suggested that it would be more interesting if the PowerPoint presentations were taped in front of a live classroom audience so that they could hear other students' comments and reactions. Other students recommended that learning would be enhanced through live interaction with both instructor and peers via the use of desktop videoconferencing technology.

A few students reported difficulty with some of the multimedia presentations due to their home computers being "too slow" or too outdated to enable utilization of all of the features of the presentations. Students without easy access to DSL or a broadband Internet connection found that their ability to access some of the online materials was limited.

\section{Student Reaction to Online Materials}

The vast majority of the social work students in this course enjoyed the face-to-face classroom experiences, but also judged the online segment quite positively. They reported being surprised at the amount of information they grasped from the practice online course segments. The following comment from one student was fairly typical:

"I can't really think of anything else. I liked the fact that the presentation included the power point, your explanation, and reading notes at the bottom. I also think the exercises you provided helped me retain the information. I think it is about as good as an online course can be. If you can't tell, I'm a little biased to the old fashioned teaching methods? But nonetheless, I thought it [the online segment] was really good.”

Another student's overall experiences with the online course modules were summarized in this way:

"It took me a couple of hours to complete but I was rewinding a lot and pausing to take notes and that is another thing that I liked about it. It didn't freeze up or anything. I really enjoyed it actually!”

Generally students found the online modules easy to understand, interesting, and informative, and loved that they could fast forward, and rewind taped sessions of the instructor. 


\section{Online Exercises and Assignments}

The course modules that were initially developed for this course were designed so that material was as interactive as possible, which required students to view and study materials online. The disadvantage was that it was difficult for students to copy or download content for viewing and/or studying the materials offline. This was a departure for students who have traditionally used the electronic medium mostly as a means to capture materials that can be downloaded and reviewed offline. As one student commented:

"I think it would be nice if all the notes for the assessment process were under one tab so I didn't have to click back and forth so many times. Then we could print the information as one document as well.”

The inability to work offline may explain why some students thought that reducing the information in the online lectures could help.

\section{Student Feedback and Comments on Course Design}

A few students commented that clicking too many buttons in the online practice modules seemed to be a lot of unnecessary work. This suggests that when too many links on a course Web site are provided, students tend to find it difficult to navigate through the materials presented, and may even find it somewhat overwhelming, and frustrating.

Other students found the online design strategy that was used to be useful and responded very positively to its interactive emphasis. They indicated that the instructional design used helped them remain organized and on task. For example, one student reported, "I felt that I was able to learn a lot from the presentations because I was able to go back and listen again if I missed a concept. I did not feel that I needed more clarification." Another reported, "I felt that all the information in the presentations was clear and concise, and it helped even further when accompanied by the PowerPoint, the quiz, and the required readings.”

\section{Student Skeptics}

Overall, the students valued the online course modules. It is important to note that, initially, many students expressed concern that the online practice modules might not be helpful for developing practice skills. In retrospect, however, even more skeptical students stated they were surprised that they learned so much about practice skills in an online setting. In summary, students participating in this project judged the online course modules effective in meeting course objectives as articulated in the course syllabus, and asserted that the online assignments contributed to their learning. One student commented:

"As with the other online assignment, I found this surprisingly effective. Perhaps I was a skeptic (yes, I was), but I have completely enjoyed this format. I believe not incorporating discussion would be a disservice to the students, however." 


\section{LIMITATIONS}

There are several caveats to the findings. This non-random single case study was exploratory in nature and findings obviously cannot be generalized. Although students in this project completed all the survey questionnaires as requested, they may have felt some pressure to frame their responses positively because they were reviewing and giving feedback on online course modules while simultaneously enrolled in a course graded by the instructor. Although student feedback was anonymous, students may still have been reluctant to be perceived as critical of the online practice course modules.

The key course assignment, consisting of three video-taped practice sessions with a colleague, was carried out in face-to-face class time. Thus, this study was not able to explore whether students could have successfully carried out a comparable skills-related assignment that they would have found as meaningful in an online setting.

Finally, the extent to which students' experience of the real classroom environment favorably disposed them toward the online segment of the course must also be taken into account. Students' impressions of a "hybrid" course are likely to be qualitatively different from students' experiences of a course that is delivered solely online, and such comparisons must be made with great caution.

\section{DISCUSSION}

\section{Lessons Learned - Students’ Perspectives}

While students indicated that they felt instructional material presented in the online course module and in the face-to-face classroom were similar in content, most reported missing the live social interaction with their classmates and the instructor. One student said, "It was similar with the same amount of information, but it lacked the interaction of the class.” The use of synchronous (i.e., live or real time) class discussions via electronic chat rooms or group conferencing software (e.g. Macromedia Breeze Meeting or Elluminate Live) might have helped students feel more connected to their peers and less isolated. The addition of webcams for video desktop conferencing might also have expanded opportunities to communicate and connect with peers, thus creating an environment similar to the more interactive cohesive learning community of a classroom (Siebert \& Spaulding-Givens, 2006).

Our experience with asynchronous discussion groups (i.e., students not present in the "virtual" classroom at the same time) received mixed results from both students and the instructor. Some students found that online asynchronous discussion groups were helpful for discussion of certain topics, but many students reported that the quality of the discussion and the interaction largely depended on the extent to which students were truly engaged in the discussion. Other students found it difficult to actively participate due to the lack of postings by group members during an assigned discussion period or at times when the group was too large for a meaningful discussion. This suggests that synchronous discussion groups might be used to enhance the quality of social interaction in an online context, and that the size of discussion groups should be limited to small groups to facilitate participation. When asynchronous groups are used, highly-focused 
discussion questions, clear criteria relative to participation and assessment of participation, and a high level of monitoring may be required by the instructor to enhance learning. Because of the high level of ongoing engagement necessary to successfully facilitate asynchronous online discussions, the use of teaching assistants should be considered if this technique is employed extensively (e.g., Siebert \& Spaulding-Givens, 2006).

\section{Lessons Learned - Instructors’ Perspective}

Even with the assistance from an excellent technical support staff and consultation from a faculty colleague with considerable online instructional design experience, the instructor found that developing online course modules was a lengthy, exhausting and rather tedious process. Having release time from regular teaching responsibilities before starting this process could have reduced these stressors. In addition, it was erroneous to assume that the first step toward online practice course development is simply to upload a number of Powerpoint Presentations and reading materials onto a course management system such as WebCT, Blackboard, or Angel. When we developed the first online course module, which primarily focused on introducing the student-learner to the online instructional environment, we discovered a number of unexpected challenges. First, we had to describe in great detail exactly how students were going to navigate and use the virtual classroom for learning purposes. Further, we had to specify what computer equipment would be needed to successfully participate in an online session, as well as provide a detailed description of how assignments were to be submitted and evaluated. This procedure took the most time for students to grasp. As a novice online instructor, the first author was quickly overwhelmed with a barrage of student e-mail messages, requiring the development of new strategies for managing the virtual classroom, such as the use of electronic drop boxes and the creation of troubleshoot discussion forums to reply to student concerns. The first author also had to spend a great deal of time learning how to monitor and retrieve student assignments in an online setting.

The immediacy of follow-up and responsiveness to 'mid-flight adjustments' created a great deal of work for the instructor, but made the developmental process student-driven, and, judging from student comments made both formally and informally, contributed to student enjoyment of learning in the online setting. The use of diverse and creative multimedia audio-visual teaching strategies also made the course visually appealing, but required a great deal of collaboration with technical support staff and a colleague experienced in instructional design.

Another valuable lesson learned was that students needed to feel that they could freely express their concerns regarding their online learning experience with the instructor. The instructor also had feel free to be herself in an online instructional environment without fear of repercussions. Initially, she was rather nervous and worried that any response made inadvertently would be recorded, and eventually come back to haunt her. As she developed her confidence, this fear subsided, and she began to value the ways the online learning environment made her more accountable as well. In an

online environment, one cannot assume that knowledge is always being clearly disseminated. For example, when teaching in a classroom environment, students benefit 
from immediate and spontaneous instructor and peer feedback to help clarify course presentations and materials. However, in an online environment, students are more reliant on the electronic medium. This requires the instructor to be particularly sensitive to how each student is interpreting and learning from the online content and format. As a result, instructors may be forced to examine course materials and presentation formats more thoroughly for clarity than they would normally do for classroom instructional materials. As such, the online instructional environment encourages "outside-the-box" thinking and testing of creative pedagogical alternatives which, in turn, enhances classroom-based instruction.

Involving students by encouraging the provision of voluntary feedback to inform the design of online course materials was a wonderful and empowering experience both for the instructor and the students. Students took more responsibility for directing their learning in the on-line course environment, and dispelled much of their own skepticism with regard to the potential effectiveness of teaching and learning practice skills online.

An equally important outcome of this process was the apparent change in the teacher-student relationship. The somewhat hierarchical relationship between the instructor and her students became more egalitarian and open as a result of this initiative. This, in turn, led to a more collegial atmosphere where both the students and the instructor formed a genuine partnership in their teaching and learning journey. Modeling openness and free expression of thought and feelings is possible when an instructor teaching in an online context is open to critical feedback.

\section{CONCLUSIONS}

The authors believe that involving students in the design and development of a course benefits both students and faculty. The development of this "hybrid" course served several important functions. 1) The experience provided a scaffolded learning experience for a novice online instructor. 2) It enhanced the development of unique online instructional materials. 3) It contributed to the instructional design process. 4) It aided to the development of criteria to better evaluate learner outcomes in an online instructional environment. 5) And finally, it encouraged students to take more responsibility for their own learning.

Empowering students and faculty to co-create new and innovative learning environments can be an effective teaching and learning strategy regardless of the instructional medium used. When students are given the opportunity to assist in collaborating in the designing of course materials, and to provide continuous evaluation throughout the process of while taking the course, it communicates to students that their feedback is valued, important, and helps to create a more tailored, responsive, and userfriendly learning environment. The authors also maintain their initial assumption that the task of designing a quality online learning environment is greatly facilitated if the instructor has also excelled in teaching in a face-to-face classroom setting. In other words, the same principles of good teaching and learning in the classroom (e.g., Chickering \& Gamson, 1987) apply to the virtual classroom. 
The most critical and unaddressed area of research concerns the task of determining whether or not students in field placements who have taken practice classes online perform as well, better, or worse than students who complete their practice classes in a more traditional face-to-face instructional format. Operationalizing this research may also prompt thoughtful educators to question deeply-held assumptions about the effectiveness of traditional classroom-based practice courses, how these might also be improved, and how learning outcomes might be better assessed. Action research is a promising tool for social work educators on this journey as it flexibly accommodates methods needed to address specific research questions, harnesses the expertise of multiple key stakeholders, and enlists us as collaborative change agents in both traditional and virtual classroom settings to address these critical issues.

\section{References}

Ballantyne N. (2007). Object lessons: A "learning object" approach to e-learning for social work education. Journal of Technology in Human Services, 25(1/2), 1-15.

Bielman, V., Putney, L., \& Strudler, N. (2000). Constructing a community in a post secondary virtual classroom. Paper presented at the annual meeting of the American Educational Research Association, New Orleans, LA.

Chickering, A. W., \& Gamson, Z. F. (1987). Seven principles for good practice in undergraduate education. AAHE Bulletin, 39(7), 3-7.

Coe, J. R., \& Elliot, D. (1999). An evaluation of teaching direct practice courses in a distance education program for rural settings. Journal of Social Work Education, 35, 353-365.

Ellsworth, A. (1999, Spring). The democratic classroom: Giving students power. NEA Higher Education Journal), 61-70; [Online] http://www.nea.org/he/heta99/s99p61.pdf

Faux, T. L., \& Black-Hughes, C. (2000). A comparison of using the internet versus lectures to teach social work history. Research on Social Work Practice, 10(4), 454466.

Fetterman, D. M. (1996). Empowerment evaluation: An introduction to theory and practice. In D. M. Fetterman, S. J. Kaftarian, \& A. Wandersman (Eds.), Empowerment evaluation: Knowledge and tools for self-assessment and accountability (pp. 3-48). Thousand Oaks, CA: Sage Publications.

George, P. (1999, Spring). Using cooperative learning in the college classroom. NEA Higher Education Journal, 33-38. [Online] http://www.nea.org/he/heta99/s99p33.pdf

Hick, S. (2002). Connecting Aboriginal learners in remote communities: An online social work course. Journal of Technology in Human Services, 20(3), 267-281.

Holden G. (2002). Delivering knowledge for practice: A world wide web-based example. Journal of Social Work Education, 38(1), 167-172. 
Huff, M. T., \& McNown-Johnson, M. (1998). Empowering students in a graduate-level social work course. Journal of Social Work Education, 34(3), 375-385.

Jaffee, D. (1998). Institutionalized resistance to asynchronous learning networks. Journal of Asynchronous Learning Networks, 2(2), 21-32.

Johansen, P., \& Ouellette, P. (2006) Integrating learning community strategies for enhancing academic and social agency partnerships in social work education. Advances in Social Work, 7(2), 101-114.

Katz-Stone, A. (2000). Online learning. Washington Based Business Journal, 18(38), 35.

Knowles, M. (1980). The modern practice of adult education: From pedagogy to andragogy. Chicago: Association Press.

Knupfer, N. N., Gram, T. E., \& Larsen, E. Z. (1997). Participant analysis of a multiclass, multistate, on-line, discussion list. (ERIC Document Reproduction Service No. ED 409-845).

Lee T. (2007). The use of information technology to enhance the quality of teaching and learning in social work practicum: An example from the City University of Hong Kong. Journal of Technology in Human Services, 25(1/2), 123-126.

Levin, H. M. (1996). Empowerment evaluation and accelerated schools. In D. M. Fetterman., S. J., Kaftarian., \& A. Wandersman (Eds.), Empowerment evaluation: Knowledge and tools for self-assessment and accountability (pp. 49-63). Thousand Oaks, CA: Sage Publications.

Macy, J. A., Rooney, R. H., Hollister, C. D., \& Freddolino, P. P. (2001). Evaluation of distance education programs in social work. Journal of Technology in Human Services, 18(3/4), 63-84.

McNutt, J. B., \& Menon, G. M. (2002). Teaching internet-based social work advocacy practice in cyberspace: A course example and conceptual framework. Electronic Journal of Social Work, 1(1), 1-6.

Menon G. M., \& Coe J. R. (2000). Technology and social work education: Recent empirical studies. Research on Social Work Practice, 10(4), 397-9.

Ouellette, P., \& Chang, V. (2004). The acquisition of social work interviewing skills in a web-based instructional environment: Preliminary findings. Advances in Social Work 5(1), 91-104.

Ouellette, P., Khaja, K., \& Westhuis, D. (2007). Developing student-sensitive online instructional materials: A collaborative process. Paper presented at the Annual Program Meeting of the Council of Social Work Educators, San Francisco, CA.

Ouellette, P., Westhuis, D., Marshall, E., \& Chang, V. (2006). The acquisition of social work interviewing skills in a Web-based and classroom instructional environment: Results of a study. Journal of Technology and Human Services, 24(4), 53-76 
Ouellette, P., \& Wilkerson, D. (2008). “They won’t come”: Increasing parent involvement in parent management training programs for at-risk youths in schools. School Social Work Journal, 32(2), 39-52.

Pethokoukis, J. M. (2002). E-learn and earn. U.S. News and World Report, 132(22), 36.

Reason, P., \& Bradbury, H. (2001). Introduction: Inquiry and participation in search of a world worthy of human aspiration. In P. Reason \& H. Bradbury (Eds.), Handbook of action research: Participative inquiry and practice (pp. 1-14). London: Sage Publications Ltd.

Sandell K. S., \& Hayes S. (2002). The Web's impact on social work education: Opportunities, challenges, and future directions. Journal of Social Work Education, 38(1), 85-99.

Saleebey, D. (2006). The strengths perspective in social work practice $\left(4^{\text {th }} \mathrm{ed}\right.$.). New York: Pearson Education Inc.

Siebert, D. C., \& Spaulding-Givens, J. (2006). Teaching clinical social work skills entirely online: A case example. Social Work Education. 25(1), 78-91.

Schrum, L. (1995). Online courses: What have we learned? Paper presented at the World Conference on Computers in Education, Birmingham, UK.

Schrum, L., \& Hong, S. (2001, April). The potential for electronic educational environments: Ensuring student success. Paper presented at the annual meeting of the American Educational Research Association, Seattle, WA.

Shibusawa, T., VanEsselstyn, D., \& Oppenheim, S. (2006). Third Space: A Web-based learning environment for teaching advanced clinical practice skills. Journal of Technology in Human Services, 24(4), 21-33.

Tallent-Runnels, M. K., Thomas, J. A., Lan, W. Y., Cooper, S., Ahern, T. C., Shaw, S. M., et al., (2006). Teaching courses online: A review of the research. Review of Educational Research, 26(1), 93-135.

Waits, T., \& Lewis, L. (2003). Distance education at degree-granting postsecondary institutions, 2001-2001. Retrieved October 10, 2007 from http://nces.ed.gov/surveys/pequis/publications/2003017/

Westhuis, D., Ouellette, P., \& Pfahler, C. (2006). A comparative analysis of two class formats for teaching and learning social work research. Advances in Social Work, 7(2), 84-100.

\section{Author's note:}

Address correspondence to: Khadija Khaja, Ph.D., Indiana University School of Social Work, 902 West New York Street, Indianapolis, IN 46202. Email: kkhaja@iupui.edu. 